\title{
MASTICATORY FUNCTION IN TEMPOROMANDIBULAR DYSFUNCTION PATIENTS: ELECTROMYOGRAPHIC EVALUATION
}

\author{
FUNÇÃO MASTIGATÓRIA EM PACIENTES COM DISFUNÇÃO TEMPOROMANDIBULAR: \\ AVALIAÇAO ELETROMIOGRÁFICA
}

Giédre BERRETIN-FELIX ${ }^{1}$, Katia Flores GENARO², Inge Elly Kiemle TRINDADE ${ }^{3}$, Alceu Sergio TRINDADE JÚNIOR ${ }^{3}$

\author{
1- DDS, MSc, PhD, Professor, Department of Speech, Language and Audiology, Bauru Dental School, University of Sao Paulo (FOB-USP), \\ Bauru, SP, Brazil. \\ 2- DDS, MSc, PhD, Associate Professor, Department of Speech, Language and Audiology, Bauru Dental School, University of Sao Paulo \\ (FOB-USP), Bauru, SP, Brazil. \\ 3- DDS, MSc, PhD, Associate Professor, Department of Biological Sciences, Bauru Dental School; University of Sao Paulo (FOB-USP), \\ Bauru, SP, Brazil.
}

Corresponding address: Department of Speech Pathology and Audiology, University of São Paulo - Al. Dr. Octávio P. Brisolla, 9-75, 17012901 - Bauru - SP - Brazil. - E-mail: gfelix@fob.usp.br

Received: February 25, 2005 - Modification: May 10, 2005 - Accepted: June 30, 2005

\begin{abstract}
7

Iemporomandibular dysfunction (TMD) is a complex disturbance that involves the masticatory muscles and/or temporomandibular joint, causing damage to the masticatory function. This study evaluated the electromyographic activity of the masseter muscle during habitual mastication of bread, apple, banana, cashew nut and paraffin film (Parafilm M) in 25 adult subjects, of both gender, with TMD. The results were compared to those of a control group, composed of 15 adult subjects, of both sexes, free of signs and/or symptoms of TMD. The MYO-TRONICS Inc., K6-I computer software was used for electromyographic processing and analyzed the following parameters: duration of the act, duration of the masticatory cycle and number of cycles. No significant differences were found between subjects in the control group and individuals with TMD as to duration of the masticatory act and of the masticatory cycle, considering all materials used for mastication. The duration of the masticatory act and cycle was longer during mastication of paraffin film in both groups. The number of masticatory cycles was higher for mastication of apple in comparison to mastication of banana, in both groups. It can be concluded that the consistency of foods influences the duration parameters of the act, duration of the cycle and the number of masticatory cycles, and the behavior of the masticatory muscles in individuals with TMD during habitual mastication is similar to that verified in individuals without TMD.

Uniterms: Mastication; Electromyography; Food; Temporomandibular joint disorders.
\end{abstract}

\begin{abstract}
RESUMO
A

disfunção temporomandibular (DTM) representa um quadro complexo que envolve os músculos mastigatórios e/ou a articulação temporomandibular, causando prejuízos à função mastigatória. Este estudo avaliou a atividade eletromiográfica do músculo masseter durante a mastigação habitual de pão, maçã, banana, castanha de caju e folha de parafilme (Parafilm M) em 25 indivíduos adultos, de ambos os gêneros, com DTM. Os resultados foram comparados com os obtidos para o grupo controle, composto por 15 indivíduos adultos, de ambos os gêneros, livres de sinais e/ou sintomas de DTM. Foi utilizado o programa computadorizado MYO-TRONICS Inc., K6-I no modo de processamento eletromiográfico, tendo sido analisados os seguintes parâmetros: duração do ato, duração do ciclo mastigatório e número de ciclos mastigatórios. Não foram encontradas diferenças estatisticamente significantes entre os indivíduos do grupo controle e com DTM no que diz respeito à duração do ato e do ciclo mastigatório, bem como o número de ciclos, considerando todos os materiais utlizados para a mastigação. A duração do ato e do ciclo mastigatório foi maior durante a mastigação de parafilme em ambos os grupos. O número de ciclos mastigatórios foi maior para a mastigação de maçã, em comparação à banana, nos diferentes grupos. Pode ser concluído que a consistência dos alimentos influencia a duração dos parâmetros duração do ato, duração do ciclo e número de ciclos mastigatórios e o comportamento dos músculos mastigatórios em indivíduos com DTM durante a mastigação habitual é semelhante à verificada em indivíduos sem disfunção. Unitermos: Mastigação; Eletromiografia; Alimentos; Transtornos da articulação temporomandibular.
\end{abstract}




\section{INTRODUCTION}

The masticatory function includes the relationship between the morphologic and functional aspects of TMJ, teeth and the neuromuscular system ${ }^{3}$. It is also influenced by the consistency and nature of foods, and one variable aspect according to consistency of the food can be the duration of the masticatory cycle ${ }^{5}$.

The basic masticatory cycles perform rhythmic and coordinated movements for breathing and swallowing, which are originated from a central pattern generator, coordinating jaw elevators and depressors and associated muscles in synergistic and antagonistic actions. Such cyclical sequences are modulated by sensory information from a variety of receptors, mainly muscle spindles and periodontal receptors ${ }^{4}$.

The behavior of masticatory muscles and information as to the functional state of the stomatognathic neuromuscular system can be obtained by electromyography. This method captures and registers the electric muscular activity, allowing achievement of parameters especially related to the duration, in milliseconds, of the action potentials during different masticatory phases. Thus, the following parameters can be analyzed: duration of the masticatory act, which includes the period between the onset and completion of muscular activity, and duration of the masticatory cycle, which includes the period between beginning of one muscular contraction and beginning of the next.

According to several authors, normal subjects present a greater number of masticatory cycles ${ }^{9}$, higher mean muscular activity $^{14}$, faster and longer duration of masticatory cycles, as well as discharge frequency and width of action potentials proportional to the increase in food consistency ${ }^{11,19}$. Such fact is an evident expression of an increase that can be considered in the recruitment of motor units and greater degree of muscular contractions as a necessary functional answer to the mastication of consistent food. According to Horio and Kawamura ${ }^{10}$, the duration of the masticatory act for hard foods is longer than that verified during mastication of other foods. On the other hand, Karkazis and Kossioni ${ }^{11}$ did not find significant differences with relation to the duration of the masticatory act for foods of different consistencies. Some works showed a decrease in the duration of the cycle when the food used presented a hard consistency ${ }^{11}$. Besides, the muscular activity at the work side is greater than at the other side ${ }^{10,15}$. Thus, the authors concluded that the consistency of foods has an effect on the parameters studied in the electromyographic activity during mastication, and these changes reflect the need for a greater level of energy to chew hard foods.

Subjects with TMD present reduction of masticatory performance ${ }^{22}$, which can be observed by the greater duration of muscular contraction ${ }^{26}$ and longer duration of masticatory cycles in comparison to a control group ${ }^{24}$. The longer duration of the masticatory cycle can be associated to the slowness verified in the mandibular movements of the group with $\mathrm{TMD}^{17}$. On the other hand, the integrated value for the masseter at the chewing side in patients was significantly smaller than in the controls for chewing at both sides $^{24}$, can be found in subjects with TMD about half contractile activity during clenching observed in healthy subjects $^{23}$ and observed lower masseter muscle activities in myogenous craniomandibular disorder patients than in the control subjects ${ }^{30}$.

According to Stholer and Ash Junior ${ }^{27}$, the factor that most contributes to the irregularities of mandibular movements in individuals with TMD is related to the variability of duration of the contact in the occlusal phase, while the discomfort during mastication can be associated to a lingering occlusal phase of the masticatory cycle. Besides, individuals with TMD can present co-contraction of the closing and opening mandibular muscles, which suggests that they can present disturbances in the activity of motor units ${ }^{8}$. A functional difference also exists between patients with strong and weak musculature, which indicates the need for individualized treatment modalities for individuals with $\mathrm{TMD}^{29}$.

Therefore, there are no consistent data regarding the neuromuscular behavior during chewing of foods of different consistencies in individuals with TMD, who present significant alterations in the masticatory function due to the dysfunction.

Thus, the objective of the present study was to evaluate the masseter muscle activity in subjects with TMD by an electromyographic surface examination, considering the parameters of duration of the act, duration of the masticatory cycle, and number of cycles during chewing of foods of different consistencies.

\section{MATERIALS AND METHODS}

\section{Subjects}

Forty adult subjects were evaluated, being 25 with previous diagnosis of TMD and the other 15 without signs or symptoms of TMD, who made up the control group. The control group was composed by 2 male subjects and 13 female subjects, aged 22 - 31 (mean age of 25).

The TMD group was composed of 21 females and 4 males, aged 17 - 60 (mean age of 28). The period of establishment of dysfunction and the diagnoses of TMD (muscle disorders, disc displacements and/or arthralgia, osteoarthritis, osteoarthrosis) varied between subjects, with those presenting pain (sharp or chronic) being the same as in the beginning of dental treatment.

\section{Procedures}

This study was initiated after approval by the Ethics Committee of Piracicaba Dental School (protocol n. 057/1998).

For the control group, subjects without TMD were considered, in agreement with the craniomandibular index of Fonseca ${ }^{7}$, whose degree of reliability is $95 \%$. Patients with TMD were diagnosed by dental clinical examination.

Electromyographic records were achieved with the subject seated in a dental chair, with the mandibular body at $45^{0}$ with the ground. The surface on the subjects' skin on 
the right and left masseter muscles and on the sternocleidomastoid muscle was cleaned with alcoholsoaked (70 GL) cotton for removal of excess oiliness.

A ground electrode (MYO-TRODE II) was positioned on the patient's neck, on the sternocleidomastoid muscle. The potentials of the masseter muscles (right and left) were captured by bipolar surface electrodes (DUO-TRODE), positioned parallel to the muscle fibers. Recordings were performed with a MYO-TRONICS INC, K6-I (Diagnostic System) computer software by electromyographic processing.

The subjects were asked to perform habitual chewing of the following foods: 1-cm in diameter of apple with peel, cut in the form of balls; 1 -cm thick slices of banana; 1 -cm thick, $1 / 4$ slice of French bread; and cashew nuts. The subjects were directed to do unilateral chewing at the right and left side using a paraffin film (Parafilm M, Laboratory Film) measuring $2 \mathrm{~cm}$ in length, $1 \mathrm{~cm}$ in width and $0.3 \mathrm{~cm}$ in thickness.

The electromyographic records during chewing of different materials were analyzed considering the following temporary parameters: duration of the act (DA) and of the masticatory cycle (DC) in milliseconds (ms), as well as the number of masticatory cycles. The records were considered completed after 15 seconds, excluding the first 2 seconds and considering the time interval for the 10 subsequent seconds. The records were measured on a digital table (Digigraf - Renoir) connected to a microcomputer.

\section{Statistical analysis}

Analysis of the data on the electromyographic evaluation was performed by two-way analysis of variance, for comparison between groups and materials, followed by the Tukey test at the 5\% significance level.

\section{RESULTS}

The values of duration of the act and duration of the masticatory cycle, as well as the number of cycles were compared, considering the different groups and the different materials used during mastication.

\section{Duration of the Masticatory Act}

The mean values for duration of the masticatory act (in $\mathrm{ms}$ ), obtained during mastication of different materials for the control and TMD groups, are presented in Table 1. The analysis of variance demonstrated no statistically significant difference between the control and TMD groups for the duration of the masticatory act.

On the other hand, there was a difference in the duration of the masticatory act for materials used in mastication, in both study groups. Considering the statistical analysis between the materials used, the paraffin differed from all others, presenting greater duration of the act, in relation to other foods.

\section{Duration of the Masticatory Cycle}

The mean values for the duration of the masticatory cycle (in ms) obtained during mastication of different materials for the control and TMD groups are displayed in Table 2.

The analysis of variance demonstrated statistically significant differences for the duration of the masticatory cycle, for the different materials used. Among the materials used, paraffin presented greater duration of the masticatory cycle, in comparison with apple, banana and cashew nut.

\section{Number of Masticatory Cycles}

The number of masticatory cycles was evaluated during mastication of paraffin, bread, apple, banana and cashew nut, for the control and TMD groups. The mean values obtained are shown in Table 3.

Analysis of the variance demonstrated no statistically

TABLE 1- Mean values (in ms) and standard deviation of the duration of the masticatory act during mastication of different materials, for the control and TMD groups

\begin{tabular}{|c|c|c|c|c|c|c|}
\hline Group & Paraffin & Bread & Apple & Banana & cashew nut & $\mathbf{n}$ \\
\hline Control & $498.67+107.85^{b}$ & $451.33+67.78^{a}$ & $457.33+86.97^{a}$ & $436.33+66.21^{a}$ & $453.00+65.38^{a}$ & 15 \\
\hline TMD & $502.00+88.43^{b}$ & $441.40+50.92^{\mathrm{a}}$ & $449.00+70.24^{a}$ & $451.80+72.33^{a}$ & $445.20+74.37^{a}$ & 25 \\
\hline
\end{tabular}

Groups with the same letters are not statistically different.

TABLE 2- Mean values (in ms) and standard deviation of the duration of the masticatory cycle during mastication of different materials, for the control and TMD groups

\begin{tabular}{|c|c|c|c|c|c|c|}
\hline Group & Paraffin & Bread & Apple & Banana & cashew nut & $\mathbf{n}$ \\
\hline Control & $841.00+183.44^{b}$ & $807.67+134.22^{a b}$ & $742.33+180.47^{a}$ & $742.00+137.58^{a}$ & $778,00+126.33^{a}$ & 15 \\
\hline DCM & $882.60+189.13^{b}$ & $796.60+105.66^{a b}$ & $773.60+133.01^{a}$ & $760.60+133.53^{a}$ & $791.20+147.71^{a}$ & 25 \\
\hline
\end{tabular}

Groups with the same letters are not statistically different. 
significant differences for the number of masticatory cycles in the control and TMD groups, yet with differences between the materials studied. From all foods analyzed, a significant difference was found between banana and apple.

\section{DISCUSSION}

Among the 25 TMD subjects, 21 (84.6\%) were of female gender. The higher incidence of TMD in women verified in this study agrees with the findings of Al-Hasson, et al. ${ }^{2}$, who observed the prevalence of women seeking treatment for TMD in relation to men. Other works evaluating subjects with TMD also found subjects of female gender to be in a greater percentage in the study population; this is related to hormonal or constitution factor, and behavior or psychological status between sexes, being, however, inconclusive as to the explanation for this finding ${ }^{6}$.

In the present work, no statistically significant differences were found between the study groups for the duration of the act and of the masticatory cycle. Thus, the results obtained demonstrated that subjects with TMD present the same muscular action compared to normal individuals, despite the neuromuscular reflexes being altered ${ }^{28}$ and the significant reduction in the average range of action potentials observed in those patients ${ }^{25}$.

On the other hand, some previous works ${ }^{17,27}$ demonstrated that duration of the period of muscular contraction and duration of masticatory cycles are increased in the group with TMD in relation to the control group. Other works verified a reduction in the duration of the act and of the masticatory cycles in individuals with TMD, as well as a decrease in the duration of muscular contraction ${ }^{24,30}$. Thus, the fact should be considered that, in the present investigation, the time between the patient's search for treatment in a TMD clinic and accomplishment of the exam might have influenced the results found, so that most patients, despite still not making use of biting plates, had already received orientation, medicines and were being aided in relation to their problem and their pain. It is important to consider that recruitment of masticatory muscles changes in the presence of pain ${ }^{20}$, and painful conditions were prevalent among the individuals evaluated, due to individual psychological characteristics, as well as the frequency, intensity and duration of occurrence of parafunctional habits.

The habitual chewing of subjects with TMD can present neuromuscular activity similar to individuals without signs and/or symptoms of dysfunction ${ }^{13}$. In agreement with Kjellberg, et al. ${ }^{12}$, the interaction between articulate and occlusal factors can result in changes in normal chewing parameters. Besides, Visser, et al. ${ }^{29}$ found functional differences in the muscular activity of individuals with TMD. On the other hand, the electrical activity of the masticatory muscles in a normal population is also heterogeneous, and there are conditions in which the chewing coordination of such individuals becomes abnormal ${ }^{18}$.

The behavior of the masticatory muscles in individuals with TMD can be evaluated considering the working and non-working sides, by calculation of the asymmetry index. Thus, Abekura, et al. ${ }^{1}$ found an increase in the asymmetry index of muscular activity according to the degree of severity of TMD. Nishigawa, et al. ${ }^{21}$ found more asymmetric levels of activity of elevating muscles of the jaw during unilateral mastication in a group with molar contact at the non-working side, when compared to the group without contact. Therefore, the methodology employed for analysis of the data can influence results, and future research on the chewing function in subjects with TMD should not only consider the muscular activity, but also the side of the pain, side with greater muscular alterations and/or the masticatory side.

Considering the several materials used, greater duration of the act and of the masticatory cycle was found for paraffin mastication, for both study groups. Thus, it was verified that masticatory parameters for a same subject using different types of foods is very similar, even though the chewing performance is influenced by characteristics of occlusion and food ${ }^{5}$. Thus, the hard material presented greater duration of the neuromuscular activity, corroborating the findings of Horio and Kawamura ${ }^{10}$ concerning the masticatory act. The results verified in that study also agree with those obtained by Nagasawa, et al. ${ }^{19}$ and Karkazis and Kossioni $^{11}$, in that the latter found greater duration of the masticatory cycle during mastication of hard foods. In agreement with Nagasawa, et al. ${ }^{19}$, masticatory rhythm can be considered one of the physiologic mechanisms of masticatory system regulations, since a faster masticatory rhythm is observed for soft foods compared to more consistent foods. This explains the extended duration of the masticatory cycle during mastication of hard foods. Besides, the changes with regard to the electromyographic parameters found during mastication contemplate the need for a greater level of energy to chew hard foods, and the adequacies to variations in food consistency are primarily achieved by modifications in chewing speed, in duration of

TABLE 3- Mean values and standard deviation for the number of masticatory cycles during mastication of different materials, for the control and TMD groups

\begin{tabular}{|c|c|c|c|c|c|c|}
\hline Group & Paraffin & Bread & Apple & Banana & cashew nut & $\mathbf{n}$ \\
\hline Control & $11.60+2.80^{\mathrm{ab}}$ & $11.33+2.53^{\mathrm{ab}}$ & $11.60+3.13^{\mathrm{b}}$ & $10.60+2.69^{a}$ & $10.87+2.26^{\mathrm{ab}}$ & 15 \\
\hline TMD & $10.96+2.39^{\mathrm{ab}}$ & $12.08+1.75^{\mathrm{ab}}$ & $12.60+2.22^{b}$ & $10.64+2.41^{a}$ & $11.56+2.77^{\mathrm{ab}}$ & 25 \\
\hline
\end{tabular}

Groups with the same letters are not statistically different. 
the masticatory cycle and in integrated electromyographic activity ${ }^{11}$.

Therefore, the sensorial information originating from intraoral mechanoreceptors to the characteristics of food can alter the mandibular movements during the masticatory cycle with regard to the direction and speed of movements, besides variations in individuals depending on factors, as habits, age, sex and occlusion ${ }^{5}$. Thus, in the present study, the increase in the duration of the act and of the masticatory cycle found during mastication of hard foods can be justified by the need for more time for muscular contraction and lower speed of mandibular movements required by the greater consistency of material used during mastication.

The number of masticatory cycles during apple mastication was greater than the number of masticatory cycles in banana mastication. Mohamed, et al. ${ }^{16}$ also found a greater number of masticatory cycles during apple mastication compared to banana. The work conducted by Horio and Kawamura ${ }^{10}$ demonstrated an increase in the number of masticatory cycles according to the increase in food consistency. The results obtained in the present study showed, as most of the mentioned works, that the increase in food consistency led to an increase in the number of masticatory cycles required before swallowing.

Concerning the masticatory function, it is fundamental that future works establish strict criteria for analysis as to the type of disturbance presented by the patient (muscle disorders, disc displacements and/or arthralgia, osteoarthritis, osteoarthrosis), characteristics of pain (sharp or chronic) and stage of treatment of the patient. It is also important to consider that the electromyographic parameters involving measurement of time are those presenting the smallest variations and that can be reproduced with greatest fidelity.

\section{CONCLUSION}

On the basis of the present findings, it can be concluded that the consistency of foods influences the duration parameters of the act, duration of the cycle and number of masticatory cycles, and the behavior of the masticatory muscles in individuals with TMD during habitual mastication is similar to that verified in individuals without TMD. In the present study, alterations were not found in the muscular activity of individuals with TMD.

\section{REFERENCES}

1- Abekura H, Kotani H, Tokuyama H, Hamada T. Asymmetry of masticatory muscle activity during intercuspal maximal clenching in healthy subjects and subjects with stomatognathic dysfunction syndrome. J Oral Rehabil. 1995;22(9):699-704.

2- Al-Hasson HK, Ismail AI, Ash MM Jr. Concerns of patients seeking treatment for TMJ dysfunction. J Prosthet Dent. 1986;56(2):21721.

3- Ash MM, Ramfjord S. Oclusão. Rio de Janeiro: Guanabara Koogan;1996. p.66-70.
4- Bakke M. Mandibular elevator muscles: phisiology, action, and affect of dental occlusion. Scand J Dent Res. 1993;101(5):314-31.

5- Bates JF, Stafford GD, Harrison A. Masticatory function - a review of the literature III. Masticatory performance and efficiency. J Oral Rehabil. 1976;3(1):57-67.

6- Dworkin SF, LeResche L. Research diagnostic criteria for temporomandibular disorders: review, criteria, examinations and specifications, critique. J Craniomandib Disord. 1992;6(4):301-55.

7- Fonseca DM. Disfunção craniomandibular (DCM): diagnóstico pela anamnese. Bauru; 1992. [Dissertação de Mestrado - Faculdade de Odontologia de Bauru da USP].

8- Hellstrand E, Hellsing G. Temporomandibular disorders: a pilot study of activation patterns and motor unit analysis of jaw muscles. Aust Prosthodont J. 1995;9:39-43.

9- Hiiemae K, Heath MR, Heath G, Kazazoglu E, Murray J, Sapper D, et al. Natural bites, food consistency and feeding behaviour in man. Arch Oral Biol. 1996;41(2):175-89.

10- Horio T, Kawamura Y. Effects of texture of food on chewing patterns in the human subject. J Oral Rehabil. 1989;16(2):177-83.

11- Karkazis HC, Kossioni AE. Re-examination of the surface EMG activity of the masseter muscle in young adults during chewing of two test foods. J Oral Rehabil. 1997;24(3):216-23.

12- Kjellberg H, Kiliaridis S, Karlsson S. Characteristics of masticatory movements and velocity in children with juvenile chronic arthritis. J Orofac Pain. 1995;9(1):64-72.

13- Kumai T. Difference in chewing patterns between involved and opposite sides in patients with unilateral temporomandibular joint and myofascial pain-dysfunction. Arch Oral Biol. 1993;38(6):46778 .

14- Mioche L, Bourdiol P, Monier S. Chewing behaviour and bolus formation during mastication of meat with different textures. Arch Oral Biol. 2003;48:193-200.

15- Miyawaki S, Ohkochi N, Kawakami T, Sugimura M. Changes in masticatory muscle activity according to food size in experimental human mastication. J Oral Rehabil. 2001 Aug;28(8):778-84.

16- Mohamed SE, Harrison JD, Christensen LV. Masticatory tooth contact patterns: cuspid and first molar contacts during mastication of three types of food. Cranio. 1996 Oct;14(4):266-73.

17- Mongini F, Tempia-Valenta G, Conserva E. Habitual mastication in dysfunction: a computer-based analysis. J Prosthet Dent. 1989 Apr;61(4):484-94.

18- Mushimoto K, Mushimoto E, Kakutani H, Nishimura I. Pilot study of the heterogeneous patterns of masticatory muscle coordination in nonpatient population. J Prosthet Dent. 1995 Dec;74(6):637-43.

19- Nagasawa T, Yabin X, Tsuga K, Abe Y. Sex difference of electromyogram of masticatory muscles and mandibular movement during chewing food. J Oral Rehabil. 1997;24(8):605-9.

20- Nielsen IL, McNeill C, Danzig W, Goldman S, Levy J, Miller AJ. Adaptation of craniofacial muscles in subjects with craniomandibular disorders. Am J Orthod Dentofacial Orthop. 1990;97(1):20-34.

21- Nishigawa K, Nakano M, Bando E. Study of jaw movement and masticatory muscle activity during unilateral chewing with and without balancing side molar contacts. J Oral Rehabil. 1997;24(9):691-6. 
22- Peroz I, Tai S. Masticatory performance in patients with anterior disk displacement without reduction in comparison with symptomfree volunteers. Eur J Oral Sci. 2002;110(5):341-4.

23- Pinho JC, Caldas FM, Mora MJ, Santana-Penin U. Electromyographic activity in patients with temporomandibular disorders. J Oral Rehabil. 2000;27(11):985-90.

24- Sato S, Goto S, Takanezawa H, Motegi K. Electromyographic and kinesiographic study in patients with nonreducing disk displacement of the temporomandibular joint. Oral Surg Oral Med Oral Pathol. 1996;81(5):516-21.

25- Sheikholeslam A, Möller E, Lous I. Pain, tenderness and strength of human mandibular elevators. Scand J Dent Res. 1980;88(1):60-6.

26- Shiau YY, Peng CC, Wen SC, Lin LD, Wang JS, Lou KL. The effects of masseter muscle pais on biting performance. J Oral Rehabil. 2003;30(10):978-84.

27- Stholer CS, ASH Junior MM Demonstration of chewing motor disorder by recording peripheral correlates of mastication. J Oral Rehabil. 1985;12(1):49-57.

28- Trindade Junior AS, Westphalen FH, Trindade IE, Maringoni RL, Atta AG. Masseteric eletromyographic silent period duration in patients with temporomandibular joint dysfunction. Braz J Med Biol Res. 1991;24(3):261-6.

29- Visser A, Kroon GW, Naeije M, Hansson TL. EMG differences between weak and strong myogenous CMD patients and healthy controls. J Oral Rehabil. 1995;22(6):429-34.

30- Visser A, McCarroll RS, Oosting J, Naeije M. Masticatory electromyographic activity in healthy young adults and myogenous craniomandibular disorders patients. J Oral Rehabil. 1994;21(1):6776. 